\title{
mir-500-Mediated GAD67 Downregulation Contributes to Neuropathic Pain
}

\author{
Zhen-Zhen Huang, ${ }^{1 \star}$ Jia-You Wei, ${ }^{1 *} \odot$ Han-Dong Ou-Yang, ${ }^{2 \star}$ Dai Li, ${ }^{1}$ Ting Xu, ${ }^{1}$ Shao-Ling Wu, ${ }^{3}$ Xiao-Long Zhang, ${ }^{1}$ \\ Cui-Cui Liu, ${ }^{3}$ Chao Ma, ${ }^{3}$ and ${ }^{\circ}$ Wen-Jun Xin ${ }^{1}$ \\ ${ }^{1}$ Zhongshan Medical School, Guangdong Province Key Laboratory of Brain Function and Disease, Sun Yat-Sen University, Guangzhou 510080, China, \\ 2Department of Anesthesiology, State Key Laboratory of Oncology in Southern China, Sun Yat-Sen Universtiy Cancer Center, Collaborative Innovation \\ Center for Cancer Medicine, Guangzhou 510060, China, and ${ }^{3}$ Department of Rehabilitation Medicine, Sun Yat-Sen Memorial Hospital, Sun Yat-Sen \\ University, Guangzhou 510120, China
}

Neuropathic pain is a common neurobiological disease involving multifaceted maladaptations ranging from gene modulation to synaptic dysfunction, but the interactions between synaptic dysfunction and the genes that are involved in persistent pain remain elusive. In the present study, we found that neuropathic pain induced by the chemotherapeutic drug paclitaxel or L5 ventral root transection significantly impaired the function of GABAergic synapses of spinal dorsal horn neurons via the reduction of the GAD67 expression. We also found that mir-500 expression was significantly increased and involved in the modulation of GAD67 expression via targeting the specific site of Gad 1 gene in the dorsal horn. In addition, knock-out of mir-500 or using mir-500 antagomir rescued the GABAergic synapses in the spinal dorsal horn neurons and attenuated the sensitized pain behavior in the rats with neuropathic pain. To our knowledge, this is the first study to investigate the function significance and the underlying molecular mechanisms of mir-500 in the process of neuropathic pain, which sheds light on the development of novel therapeutic options for neuropathic pain.

Key words: GAD67; L5 ventral root transection; mir-500; neuropathic pain; paclitaxel

\section{Significance Statement}

Neuropathic pain is a common neurobiological disease involving multifaceted maladaptations ranging from gene modulation to synaptic dysfunction, but the underlying molecular mechanisms remain elusive. The present study illustrates for the first time a mir-500-mediated mechanism underlying spinal GABAergic dysfunction and sensitized pain behavior in neuropathic pain induced by the chemotherapeutic drug paclitaxel or L5 ventral root transection, which sheds light on the development of novel therapeutic options for neuropathic pain.

\section{Introduction}

MicroRNAs (miRNAs) are an evolutionarily conserved class of small, noncoding RNAs that is involved in diverse biological processes including cellular proliferation and differentiation as negative regulators of gene expression (Filipowicz et al., 2008). Generally, miRNAs inhibit the translation of specific genes in a sequence-dependent manner via recognition of the $3^{\prime}$-UTR se-

\footnotetext{
Received Feb. 22, 2016; revised April 28, 2016; accepted April 28, 2016.

Author contributions: W.X. designed research; Z.-Z.H., J.-Y.W., H.-D.O.-Y., D.L., T.X., S.-L.W., X.-L.Z., C.-C.L., and C.M. performed research; Z.-Z.H., J.-Y.W., and H.-D.O.-Y. analyzed data; W.X. wrote the paper.

This work was supported by the National Natural Science Foundation of China (Grants 81271474, 81300966, and 81171469) and the Fundamental Research Funds for the Central Universities (Grant 15ykjco4b).

The authors declare no competing financial interests.

*Z.-Z.H., J.-Y.W., and H.-D.O.-Y. contributed equally to this work.

Correspondence should be addressed to Wenjun Xin, Zhongshan Medical School, Guangdong Province Key Laboratory of Brain Function and Disease, Sun Yat-Sen University, 74 Zhongshan Rd. 2, Guangzhou, China. E-mail: xinwj@mail.sysu.edu.cn.

DOI:10.1523/JNEUROSCI.0646-16.2016

Copyright $\odot 2016$ the authors $\quad 0270-6474 / 16 / 366321-11 \$ 15.00 / 0$
}

quence of the target messenger RNAs (Bartel, 2009). Recently emerging studies suggested the potential role of miRNAs in the development and maintenance of hyperalgesia and/or allodynia induced by peripheral inflammation or nerve injury (Bai et al., 2007; Genda et al., 2013; Sengupta et al., 2013; Elramah et al., 2014), whereas the intracellular processes largely remained elusive. For instance, reduction of selective mature miRNAs (e.g., mir-124) in sensory neurons was reported in the rats with inflammatory muscle pain (Bai et al., 2007) or sciatic nerve injury (Wu et al., 2011), whereas intrathecal injection of mir-124 had an obvious anti-nociceptive effect in rodents with inflammation or nerve injury (Willemen et al., 2012). Interestingly, a recent study showed an upregulation of mir-500 in the bladder smooth muscle cells in patients with bladder pain syndrome (Sanchez Freire et al., 2010). Currently, whether mir-500 is involved in the neuropathic pain induced by chemotherapeutic drugs or nerve injury, as well as the pathophysiological involvement of mir-500 in the setting of neuropathic pain, remains unclear. 
Processing of nociceptive information in the spinal dorsal horn is modulated substantially by the local GABAergic and glycinergic inhibitory circuits. It was reported that intrathecal treatment of the GABA receptor antagonist produced remarkable hypersensitivity to innocuous tactile stimuli (Malan et al., 2002; Gwak et al., 2006) and transgenic mice lacking specific subunits of the GABA receptor developed hyperalgesia and allodynia (Schuler et al., 2001). GABA is synthesized from glutamate by two isoforms of glutamate decarboxylase (GAD), GAD67 and GAD65, which are encoded by two separate genes, Gad1 and Gad2, respectively. GAD67 is distributed throughout the cell, whereas GAD65 localizes preferentially in synaptic terminals (Esclapez et al., 1994). Studies have shown that GAD67 was responsible for $>90 \%$ of basal GABA synthesis (Asada et al., 1997) and knock-down of Gad1, but not Gad2, resulted in cell-autonomous deficits in axon branching, perisomatic synapse formation, and complexity of the innervation fields (Chattopadhyaya et al., 2007), suggesting a specific role of GAD67 in maintining proper neural function. Furthermore, depletion of Gad1 markedly reduced the amplitude and frequency of miniature IPSCs (mIPSCs) in central neurons (Lau and Murthy, 2012) and chronic constriction of the sciatic nerve significantly decreased the expression of GAD67 (Vaysse et al., 2011). These results implied the potential involvement of GAD67 downregulation in the adaptation of spinal nociceptive circuits in the setting of neuropathic pain. Currently, whether GAD67 contributes to neuropathic pain and the underlying mechanism remained unclear. The present study focused on the mechanism of mir-500mediated modulation of GAD67 and its functional significance in rodent models with neuropathic pain induced by paclitaxel or L5 ventral root transection (L5-VRT).

\section{Materials and Methods}

Animals. Male Sprague Dawley rats (180-230 g) were obtained from Sun Yat-Sen University Animal Care and Use Committee. To examine the role of mir-500 in neuropathic pain, we create rno-mir-500 knock-out (KO) Sprague Dawley rats by microinjection of TALENs in fertilized eggs (Cyagen Biosciences). Briefly, the rno-mir-500 gene (Gene ID: 100314112; MirBase accession no. MIMAT0005321), which was located on rat chromosome $\mathrm{X}$, was selected as the TALEN target site. TALENs were constructed using the Golden Gate Assembly and confirmed by sequencing. TALEN mRNA, generated by in vitro transcription, was injected into fertilized eggs for $\mathrm{KO}$ rat production. The founders, which were missing 13 bases in the both strands compared with the wild-type (WT) DNA sequence, were genotyped by PCR followed by DNAsequencing analysis. After that, heterozygous F1 were produced by mating F0 with WT rats. Heterozygous F1 rats were determined and mated to produce F2. Homozygote F2 (mir-500 ${ }^{-1-}$ ) and WT (mir-500 ${ }^{+/+}$) was determined by DNA-sequencing analysis (see Fig. 5A). All animals were housed in a temperature-controlled room $\left(22 \pm 1^{\circ} \mathrm{C}\right)$ with a $12 \mathrm{~h} \mathrm{light/}$ dark cycle. All animal experimental procedures were approved by local Animal Care and Use Committee and performed in accordance with the animal care and ethical guidelines of National Institutes of Health.

Reagents and L5-VRT. Paclitaxel (Taxol; Bristol-Myers Squibb, $6 \mathrm{mg}$ / $\mathrm{ml}$ ) was diluted with saline (1:3) and injected $(8 \mathrm{mg} / \mathrm{kg}$, i.p., cumulative dose of $24 \mathrm{mg} / \mathrm{kg}$ ) on 3 alternate days (days 1, 4, and 7). The cholesterolconjugated mir-500 antagomir and antagomir control were obtained commercially from Ribobio for the in vivo experiments. mir-500 mimic for the in vitro experiments was also purchased from Ribobio.

L5-VRT model was performed as described previously (Li et al., 2002; Zang et al., 2015). Briefly, surgery was performed on rats under deep anesthesia after intraperitoneal administration of sodium pentobarbital (50 mg/kg). An L5 hemilaminectomy was performed to expose the L5 nerve root. The ventral root was gently pulled out with fine forceps and transected 2-3 mm proximal to the DRG and a small portion $(2 \mathrm{~mm})$ of the root was dissected. In the sham group, an identical operation was performed for exposure of the L5 ventral root, but the nerve was not transected.

Intrathecal application of miRNA modulators and behavioral test. Intrathecal injection of mir-500 antagomir $(0.5 \mathrm{nmol} / \mathrm{d})$ was performed according to previously described methods ( $\mathrm{Li}$ et al., 2015). In brief, a polyethylene-10 catheter was inserted into the rat's subarachnoid space through L5 to L6 spinal cord segmental intervertebral space and the tip of the catheter was located at the L5 spinal segmental level. mir-500 antagomir was intrathecal injected $30 \mathrm{~min}$ before the first dose of paclitaxel or L5-VRT surgery and continued for $5 \mathrm{~d}$.

The withdrawal threshold of the hindpaw was determined by applying mechanical stimuli to the plantar surface of the hindpaw using Von Frey hairs. The $50 \%$ withdrawal threshold was defined as the lowest force that produced five or more responses of 10 stimuli (Liu et al., 2010).

Thermal hyperalgesia was tested using a plantar test (7370; Ugo Basile Plantar Test Apparatus) as described previously (Hargreaves et al., 1988). Briefly, a radiant heat source beneath a glass floor was aimed at the plantar surface of the hindpaw. Three measurements of hindpaw withdrawal latency were taken for each hindpaw in each test session. The hindpaw was tested alternately with $>5$ min intervals between the consecutive tests. Three measurements of latency per side were averaged as the result of each test. A $20 \mathrm{~s}$ cutoff was set to prevent the tissue damage. The experimenter who conducted the behavioral tests was blinded to all treatments.

Application of miRNA modulators in glioma cell line C6. Malignant glioma cell line C6 was cultured in regular medium (DMEM with 10\% fetal bovine serum and $1 \%$ antibiotics). Then, 20 pmol of mir-500 mimic and scrambled control miRNA (Ribo) were transfected into C6 cells in 24-well plates using Lipofectamine 2000 (Invitrogen) according to the manufacturer's instructions. The expression of GAD67 was examined using the Western blot method $1 \mathrm{~d}$ after transfection.

RNA isolation and microarray experiments. Total RNA was extracted from spinal dorsal horn tissue using TRIzol reagent (Invitrogen). RNA labeling and hybridization on miRNA microarray chips were conducted as described previously (Liu et al., 2004a). Briefly, the purified RNA using the mirVANA miRNA Isolation Kit (Applied Biosystems) was labeled with fluorescein and hybridization was performed on miRNA microarray chips (miRNA microarray V4.0; CapitalBio) containing 1965 probes in triplicate. These probes corresponded to 988 human, 627 mice, and 350 rat miRNA genes designed based on the miRBase Release 12.0. Three independent RNA samples on different time points from spinal dorsal horn tissue in the rats treated with paclitaxel or vehicle were hybridized with miRNA microarrays separately. Hybridization intensity values from individual samples were filtered and normalized to per-chip mean values. We considered candidate miRNAs with a signal $>500$ as positive.

Western blot. Western blot analyses were performed as described previously (Huang et al., 2014; Li et al., 2015). Briefly, lysates of spinal dorsal horn tissues or cells were prepared and separated by gel electrophoresis (SDS-PAGE) and transferred onto a polyvinylidene fluoride membrane. The blots were placed in blocking buffer for $1 \mathrm{~h}$ at room temperature and incubated with primary antibody against GAD67 (1:1000; Abcam) overnight at $4^{\circ} \mathrm{C}$. The blots were then incubated with horseradish peroxidaseconjugated IgG. Electrochemiluminescence (Pierce) was used to detect the immune complex. The band was quantified with computer-assisted imaging analysis system (ImageJ).

Plasmid construction and luciferase reporter assay. A luciferase reporter assay was performed to test the binding of mir-500 to its target gene Gad1. A 1233 bp segment of rat Gad1 3'-UTR containing a presumed mir-500 complementary site (seed sequence, GTGCAT) was amplified by PCR using rat cDNA as a template. The PCR products were inserted into the psi-CHECK2 plasmid (Applied Biosystems) and efficient insertion was confirmed by sequencing. To test the binding specificity, the seed sequence of mir-500 was mutated from GTGCAT to CACGTA (see Fig. $2 H$ ). For the luciferase reporter assays, $0.5 \mu \mathrm{g}$ of firefly luciferase reporter plasmid and 20 pmol of mir-500 mimic and scrambled control miRNA (Ribo) were transfected into 293T cells in 24-well plates using Lipofectamine 2000 (Invitrogen) according to the manufacturer's instruction. The b-gal vector was used as a transfection control. One day after transfection, the cells were assayed using the Dual-Luciferase Re- 
porter Assay System (Promega). Briefly, cells were lysed with $35 \mu \mathrm{l}$ of passive lysis buffer per well. The culture plate was incubated for $15 \mathrm{~min}$ with shaking at $400 \mathrm{rpm}$ at room temperature. To record luminescence, $100 \mu \mathrm{l}$ of Luciferase Assay Reagent II was added to $30 \mu \mathrm{l}$ of lysate for first measurement (firefly luciferase) and $100 \mu \mathrm{l}$ of Stop \& Glo Reagent was added for the second measurement (Renilla luciferase). The Renilla/firefly luciferase ratio was used for statistical analysis. Three to four replicate wells were used in each experiment

FISH and immunohistochemistry. Animals were anesthetized with sodium pentobarbital $(50 \mathrm{mg} / \mathrm{kg}$, i.p. $)$ and perfused transcardially with $4 \%$ paraformaldehyde in $0.1 \mathrm{~m}$ DEPC-PBS. The lumbar enlargement of spinal cord was removed, postfixed with the same fixative for $24 \mathrm{~h}$ at $4^{\circ} \mathrm{C}$, and paraffin embedded. FISH analysis was performed according to the manufacturer's guidelines. Briefly, the spinal cord tissues were cut into $10-\mu \mathrm{m}$-thick transverse sections and washed with $75 \%$ alcohol. The sections were then hybridized at $42^{\circ} \mathrm{C}$ for $24 \mathrm{~h}$ with $5^{\prime}$-digoxigenin-labeled mir-500 oligonucleotide probe (1:800, EXQON). Sections were washed and incubated with blocking buffer for $60 \mathrm{~min}$ at room temperature. Sections were incubated at $4^{\circ} \mathrm{C}$ overnight with anti-digoxigenin-POD polyclonal antibody (1:500; Roche) and GAD67 antibody (1:200; Santa Cruz Biotechnology). Sections were then incubated with TSA Plus Fluorescein (1:250; PerkinElmer) and Alexa Fluor 555-conjugated secondary antibody (1:500; Thermo Fisher) at $37^{\circ} \mathrm{C}$ for $30 \mathrm{~min}$. The stained sections were then examined with a Zeiss confocal microscope equipped with a digital camera (Zeiss). The quantification of immunofluorescence staining was performed by counting the number of mir-500 and GAD67-immunoreactive positive cells in each section. The proportion of mir-500-expressing GABAergic neurons was determined as the number of mir-500- and GAD67-positive cells divided by the total number of GAD67-positive cells. In each rat, every fourth section was picked from a series of consecutive sections and four sections were counted. An average proportion of mir-500-expressing GABAergic neurons were obtained.

For GAD67 staining, sections $(16 \mu \mathrm{m})$ were cut and processed for immunohistochemistry with primary antibody for GAD67 (1:200; Santa Cruz Biotechnology). After incubation overnight at $4^{\circ} \mathrm{C}$, the sections were incubated with fluorescein isothiocyanate-conjugated secondary antibodies for $1 \mathrm{~h}$ at room temperature. The stained sections were then examined with a Leica fluorescence microscope and images were captured with a Leica DFC350 FX camera. For quantification of GAD67 immunostaining, the immunoreactive-positive area was analyzed with a Leica Qwin V3 image system.

PCR amplification of miRNAs and $m R N A s$. Stem-loop qRT-PCR assays using TaqMan miRNA probes (Applied Biosystems) to quantify mature miRNAs were performed, as previously reported (Chen et al., 2005; Li et al., 2009). Real-time PCR was performed using a TaqMan PCR kit and the Applied Biosystems 7500 Sequence Detection System with the following conditions: $95^{\circ} \mathrm{C}$ for $10 \mathrm{~min}, 60$ cycles of $95^{\circ} \mathrm{C}, 15 \mathrm{~s}$, and $60^{\circ} \mathrm{C} 1 \mathrm{~min}$. All reactions, including no-template controls, were run in triplicate. The relative expression ratio of miRNA in the rat's spinal tissues was quantified using the $2^{-\delta \delta \mathrm{CT}}$ method.

To detect the mRNA of GAD67, real-time qRT-PCR was performed using SYBR Green qPCR SuperMix (Invitrogen) and the ABI PRISM7500 Sequence Detection System. The reactions were set up based on the manufacturer's protocol. PCR conditions were as follows: incubation at $95^{\circ} \mathrm{C}$ for 3 min, followed by 40 cycles of thermal cycling $\left(10 \mathrm{~s}\right.$ at $95^{\circ} \mathrm{C}, 20 \mathrm{~s}$ at $58^{\circ} \mathrm{C}$, and $10 \mathrm{~s}$ at $72^{\circ} \mathrm{C}$ ). All primers used are listed in Table 1.

Spinal cord slice preparation and patch-clamp recording. Spinal cord slices were prepared and whole-cell patch-clamp recording was performed as described previously with minor adjustments (Moore et al., 2002; Huang et al., 2014). Briefly, male Sprague Dawley rats (age 25-35 d) were deeply anesthetized with sodium pentobarbital (50 mg/kg, i.p.) and the spinal cord was quickly removed into ice-cold incubation solution consisting of the following (in $\mathrm{mM}$ ): $95 \mathrm{NaCl}, 1.8 \mathrm{KCl}, 1.2 \mathrm{KH}_{2} \mathrm{PO}_{4}$, $0.5 \mathrm{CaCl}_{2}, 7 \mathrm{MgSO}_{4}, 26 \mathrm{NaHCO}_{3}, 15$ glucose, and 50 sucrose, oxygenated with $95 \% \mathrm{O}_{2} / 5 \% \mathrm{CO}_{2}, \mathrm{pH} 7.4$, at a measured osmolarity of 310-320 $\mathrm{mOsm} / \mathrm{L}$. The dura mater and the ventral roots were removed. Parasagittal slices with attached dorsal roots $(10-15 \mathrm{~mm}$ long) were cut at $400-$
Table 1. Specific primer sequences

\begin{tabular}{|c|c|c|}
\hline Gene & Primer & Sequence \\
\hline \multirow[t]{2}{*}{ rno-mir-181 } & Forward & 5'-GCCCAACATTCAACGCTGTC-3' \\
\hline & Reverse & $5^{\prime}$-GTGTCGTGGAGTCGGCA-3' \\
\hline \multirow[t]{2}{*}{ rno-mir-188 } & Forward & 5'-GCCCCATCCCTTGCATGG-3' \\
\hline & Reverse & 5'-GTGTCGTGGAGTCGGCA-3' \\
\hline \multirow[t]{2}{*}{ rno-mir-331 } & Forward & 5'-GCCCGCCCCTGGGCCTAT-3' \\
\hline & Reverse & 5'-GTGTCGTGGAGTCGGCA-3' \\
\hline \multirow[t]{2}{*}{ rno-mir-500 } & Forward & 5'-GCCCAATGCACCTGGGCAA-3' \\
\hline & Reverse & 5'-GTGTCGTGGAGTCGGCA-3' \\
\hline \multirow[t]{2}{*}{ U6 } & Forward & 5'-CTCGCTTCGGCAGCACA-3' \\
\hline & Reverse & 5'-AACGCTTCACGAATTTGCGT-3' \\
\hline \multirow[t]{2}{*}{ GAD67 } & Forward & 5'-САCCTCTTCTCACAACCAACG-3' \\
\hline & Reverse & 5'-GACTCTTCTCTTCCAGGCTATTG-3' \\
\hline \multirow[t]{2}{*}{$\beta$-actin } & Forward & $5^{\prime}$-AGGGAATCGTGCGTGACAT-3' \\
\hline & Reverse & 5'-GAACCGCTCATTGCCGATAG-3' \\
\hline
\end{tabular}

$600 \mu \mathrm{m}$ thickness using a vibrating microslicer (DTK-1000; Dosaka) and kept in the incubation solution at $33^{\circ} \mathrm{C}$ for at least $60 \mathrm{~min}$. After incubation, an individual slice with attached dorsal root was transferred to a recording chamber and continually perfused with oxygenated ACSF solution at room temperature. The dorsal root was gently led into the suction electrode. Lamina I-II neurons were visualized using a $60 \times$ water-immersion objective on an upright infrared Nikon microscope. EPC-10 amplifier and the PULSE program (HEKA Electronics) were used with a pipette $(4-6 \mathrm{M} \Omega$ ) with internal solution containing the following (in mM): $120 \mathrm{CsSO}_{4}, 20$ TEA-Cl, $2 \mathrm{MgCl}_{2}, 2 \mathrm{Na}_{2} \mathrm{ATP}, 10$ EGTA, 0.5 NaGTP, biocytin 5, 10 HEPES, pH 7.28, with CsOH at a measured osmolarity of $300 \mathrm{mOsm} / \mathrm{L}$. Stimulation was applied to the attached dorsal roots at $0.1 \mathrm{~ms}$ pulse width via a suction electrode with an isolated current stimulator (A360; World Precision Instruments). The neurons were voltage clamped at a holding potential of $0 \mathrm{mV}$, thus minimizing the contribution of NMDA and AMPA/kainite receptor-mediated events (Yoshimura and Nishi, 1993; Baccei and Fitzgerald, 2004). After incubation with $1 \mu \mathrm{M}$ strychnine, IPSCs were evoked by stimulating the attached dorsal root via the suction electrode. At the end of all experiments, bicuculline $(10 \mu \mathrm{M})$ was bath applied and completely blocked IPSCs, confirming that the recorded currents were mainly mediated by $\mathrm{GABA}_{\mathrm{A}}$ receptors. For GABAergic mIPSCs, slices were incubated with antagonists of glycinergic and glutamatergic ionotropic transmission $[1 \mu \mathrm{M}$ strychnine, $50 \mu \mathrm{M}$ D-(-)-2-amino-5-phosphonopentanoic acid, and $10 \mu \mathrm{M}$ 6-cyano-7nitroquinoxaline-2,3-dione] and were recorded in the presence of lidocaine $(2 \mathrm{~mm})$ to block action-potential-dependent effects. In all experiments, only one neuron per spinal cord slice was used.

Statistical analysis. All data are expressed as means \pm SD and were analyzed using SPSS version 13.0 software. Western blot, qRT-PCR, and electrophysiological data were analyzed by two-way ANOVA followed by Tukey's post hoc test. For behavioral analysis, one-way or two-way ANOVA with repeated-measures followed by Tukey's post hoc test was performed. The criterion for statistical significance was $p<0.05$. The sample size was based on our and others' experience in painful behavior studies to provide power analysis.

\section{Results}

\section{Decreased GABAergic synaptic function and GAD67} expression in superficial dorsal horn is induced by paclitaxel or L5-VRT

We first examined the change of GABAergic inhibitory synaptic connections in superficial spinal dorsal horn of the rats with persistent hyperalgesia and allodynia induced by paclitaxel. Paclitaxel ( $3 \times 8 \mathrm{mg} / \mathrm{kg}$; cumulative dose, $24 \mathrm{mg} / \mathrm{kg}$ ) induced chronic marked thermal hyperalgesia (Fig. $1 A$ ) and mechanical allodynia (Fig. $1 B$ ) on days 4,6 , and $10 \mathrm{~d}$, but not day 1 , compared with the vehicle group. Next, we found that the slope of the input-output curve for GABAergic IPSCs was decreased in superficial dorsal 
A

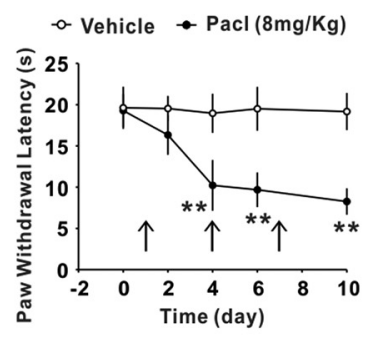

C
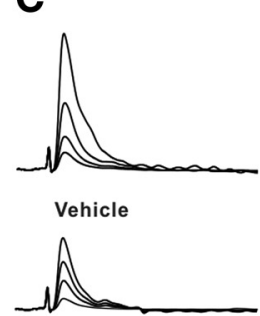

Day $4 / \mathrm{Pacl}$

$\mathbf{E}$

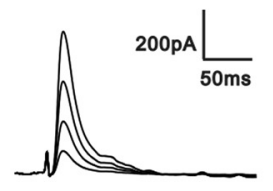

Day $1 / \mathrm{Pacl}$

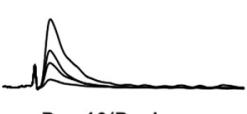

Day $10 / \mathrm{Pacl}$

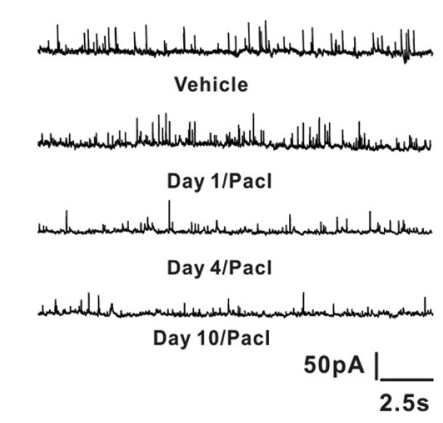

B
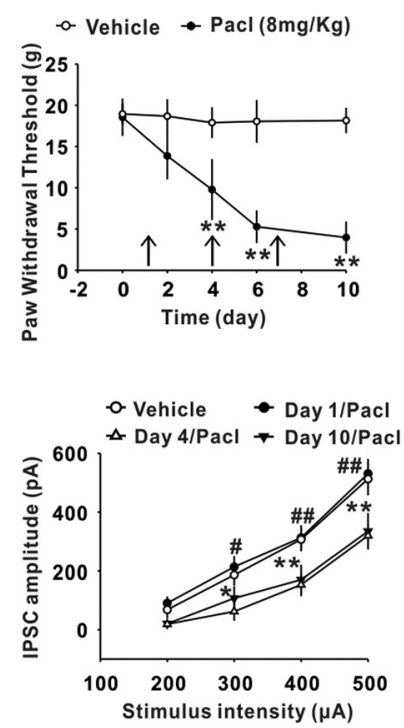

D

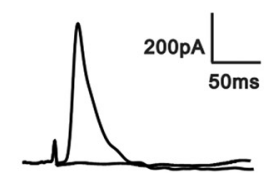

$\mathbf{F}$
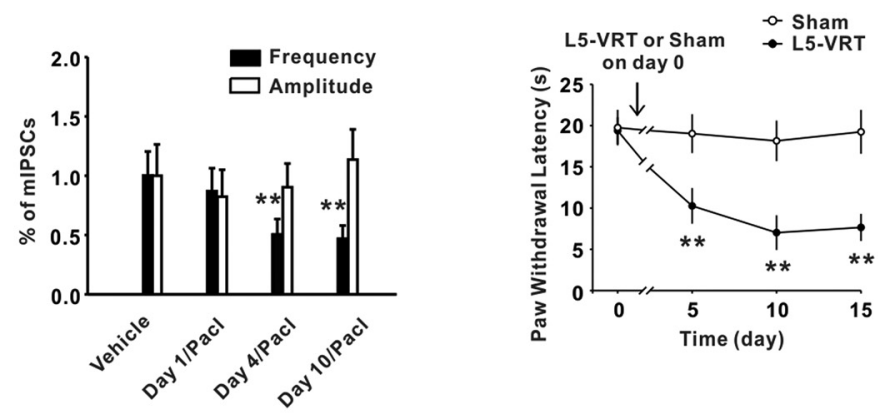

G

H
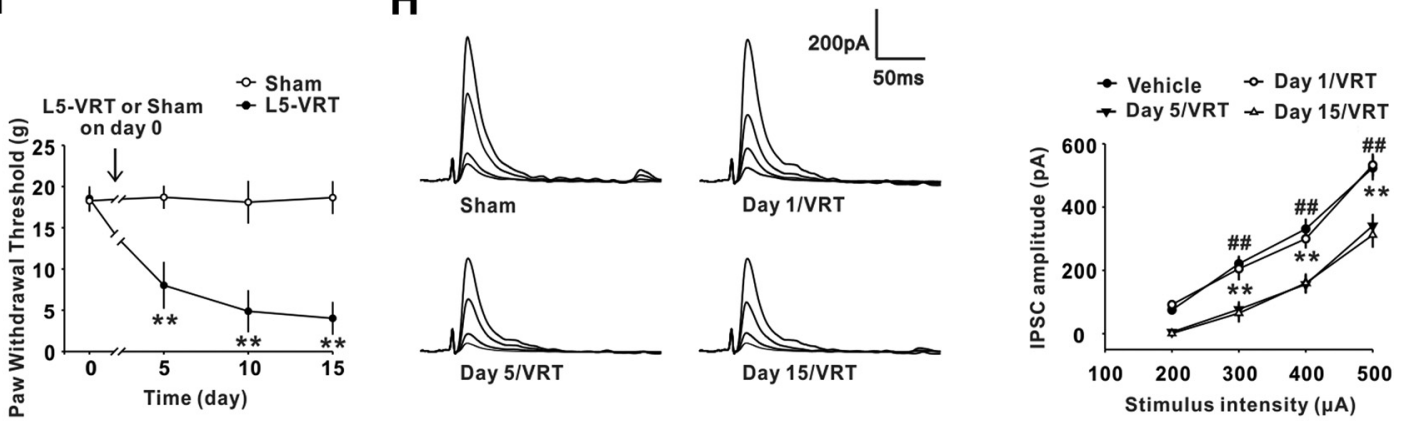

I
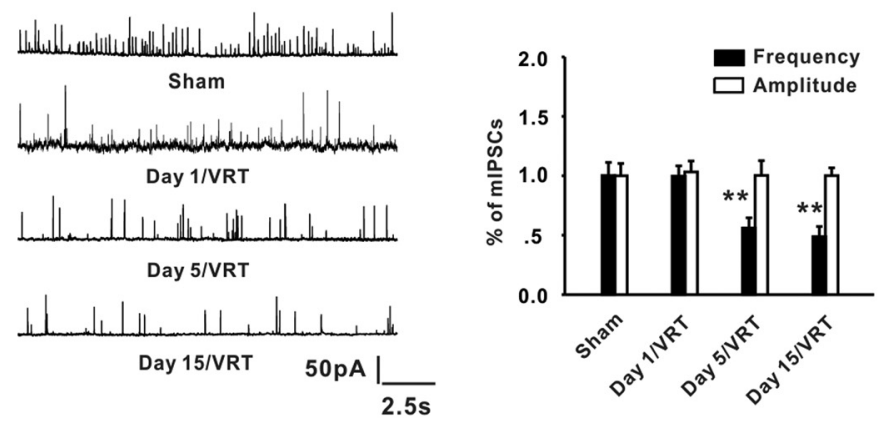

Figure 1. Persistent pain decreases GABAergic synaptic function by inhibiting presynaptic GABA release. $\boldsymbol{A}, \boldsymbol{B}$, Time course of changes in withdrawal latency and withdrawal threshold after intraperitoneal paclitaxel injection. ${ }^{* *} p<0.01$ versus the vehicle group; $n=12$ in each group. $C$, Representative traces of GABA IPSCs evoked by various stimulation intensities in spinal superficial dorsal horn neurons. ${ }^{*} p<0.05,{ }^{* *} p<0.01$ on $\mathrm{d} 4$ after paclitaxel group versus the corresponding vehicle group. \#p $<0.05$, \#\# $<0.01$ on d 10 after paclitaxel (Figure legend continues.) 
A
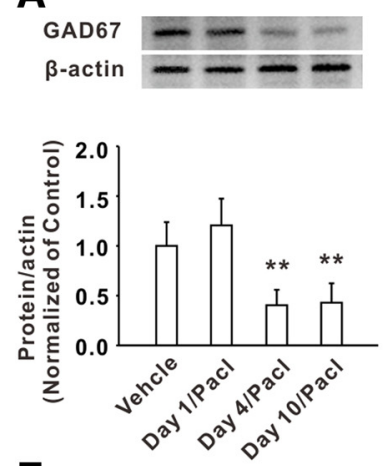

E

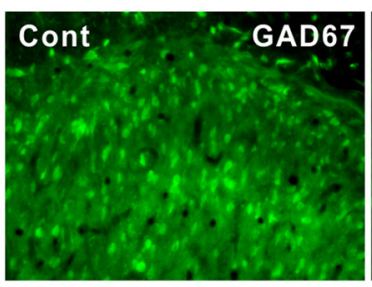

B
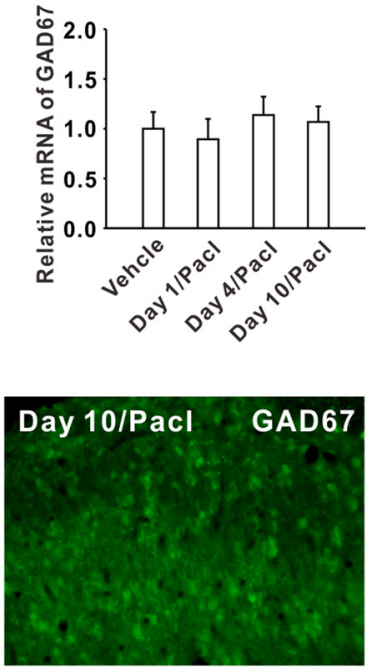

C

GAD67

$\beta$-actin
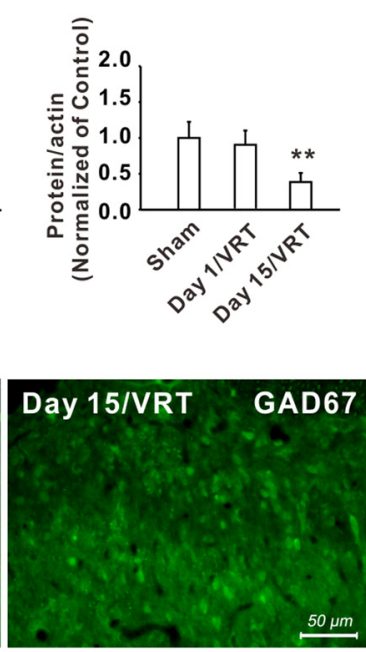

D
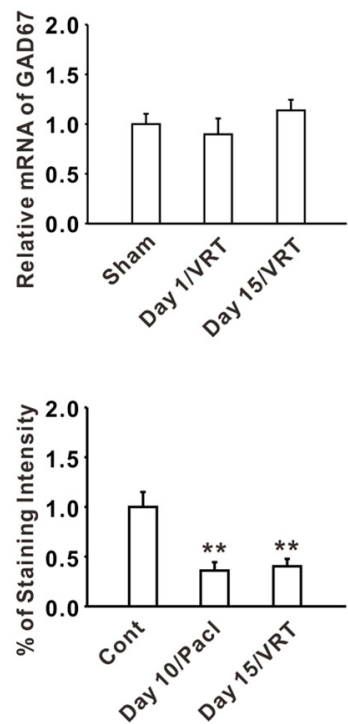

Figure 2. The GAD67 protein, but not mRNA, is decreased by persistent pain. $A$, Representative blots and histogram showing downregulation of GAD67 induced by paclitaxel treatment. ${ }^{* *} p<$ 0.01 versus corresponding vehicle group. $n=6$ in each group. $\boldsymbol{B}$, Paclitaxel treatment did not affect the mRNA level of GAD67. $n=6$ in each group. $\boldsymbol{C}$, Western blots and group data of GAD67 protein in L5-VRT rats. ${ }^{* *} p<0.01$ versus corresponding sham group. $n=6$ in each group. $D$, Analysis of GAD67 mRNA level after L5-VRT. $n=6$ in each group. E, Immunohistochemical analysis revealing decreased GAD67 levels in the superficial dorsal horn after paclitaxel treatment or L5-VRT. $n=6$ in each group.

horn neurons at day 4 and 10, but not day 1, after paclitaxel injection (Fig. 1C). Notably, the evoked IPSCs were completely blocked by bath application of bicuculline (Fig. 1D). Importantly, the reduced frequency of mIPSCs (Fig. $1 E$ ) was observed in the superficial dorsal horn neurons at days 4 and 10 after injection of paclitaxel. These results further confirmed that paclitaxel treatment reduced the presynaptic GABA releases in the dorsal horn and mediated the chronic pain. The study also showed that LF-VRT, another rodent model of chronic neuropathic pain (Li et al., 2002; Zang et al., 2015), significantly induced the persistent thermal hyperalgesia (Fig. $1 F$ ) and mechanical allodynia (Fig. 1G). Furthermore, similar to the results in the paclitaxel-treated rats, the slope of the input-output curve for GABAergic IPSCs (Fig. $1 H$ ) and the frequency of mIPSCs (Fig. 1I) were significantly decreased on day 5 and 15 , but not day 1, after L5-VRT compared with the sham group. These results indicated a decreased presynaptic GABA release onto the superficial dorsal horn neurons and persistent pain-related behavior induced by paclitaxel or VRT.

Depletion of GAD67 led to a 93\% reduction in GABA levels, which suggested the critical role of GAD67 in the synthesis of GABA neurotransmitter (Asada et al., 1997; Martin, 2000). We then determined the level of GAD67 protein and mRNA in the

\section{$\leftarrow$}

(Figure legend continued.) group versus corresponding vehicle group. $n=21$ in each group. $\boldsymbol{D}$, IPSCS were abolished by bicuculline. $\boldsymbol{E}$, Representative traces of mIPSCs in neurons from the four groups ( $n=60$ cells for each group). $\boldsymbol{F}, \mathbf{G}$, Time course of changes in withdrawal latency and withdrawal threshold after L5-VRT treatment. ${ }^{* *} p<0.01$ versus the sham group. $n=12$ in each group. $\boldsymbol{H}$, Representative traces of GABA IPSCs evoked by various stimulation intensities in spinal superficial dorsal horn neurons. ${ }^{* *} p<0.01 \mathrm{~d} 4$ after L5-VRT group versus corresponding vehicle group. \#\#p $<0.01 \mathrm{~d} 10$ after L5-VRT group versus corresponding vehicle group $n=21$ in each group). $I$, Representative traces of mIPSCs in neurons from the L5-VRT or sham groups. $n=49$ cells for each group. spinal dorsal neurons after the development of persistent pain. Although the expression of GAD67 protein was significantly decreased at days 4 and 10 (Fig. 2A), the GAD67 mRNA was not significantly changed at any time point (Fig. $2 B$ ) after paclitaxel injection. Similarly, the levels of GAD67 protein were also decreased at day 15 (Fig. 2C) and the mRNA level was not changed after L5-VRT surgery (Fig. 2D). Immunohistochemical analysis further revealed that GAD67 was downregulated throughout the superficial dorsal horn on day 10 after paclitaxel treatment or on day 15 after VRT surgery (Fig. 2E). These results suggested that a potential posttranscriptional mechanism was involved in the GAD67 downregulation in neuropathic pain induced by paclitaxel or L5-VRT.

\section{Increased mir-500 regulates GAD expression through the predicted sites}

Noncoding RNAs, including miRNAs, repress gene expression at the posttranscriptional level through binding, usually at the 3 'UTR of a target mRNA, thereby providing a dynamic brake on the protein synthesis (Kim et al., 2009). To identify the potential involvement of miRNAs in the pathogenesis of neuropathic pain, we collected the tissue of L4-L6 spinal dorsal horn at days 4 and 10 after paclitaxel treatment and performed genome-wide miRNA screening to detect the change in miRNAs. Because we were interested in the mechanism underlying GAD67 reduction in the spinal dorsal horn, two conditions, the potential binding site from databases of TargetScan and miRanda analysis and at least 2.5-fold upregulation of miRNAs, were set as the criteria to screen the target miRNAs. The results showed that 35 miRNAs of the total 350 were increased with a $>2.5$-fold change on days 4 and 10 after paclitaxel treatment (Fig. $3 A$ ) and 4 miRNAs, including mir-500, mir-188, mir-181, and mir-331, were related to GAD67 expression from the analysis of these 2 criteria (Fig. $3 B$ ). qRT-PCR analyses further showed that mir-500 was significantly 
A

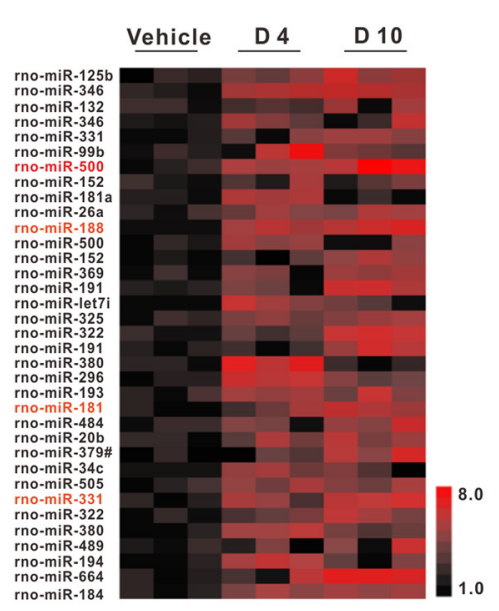

D

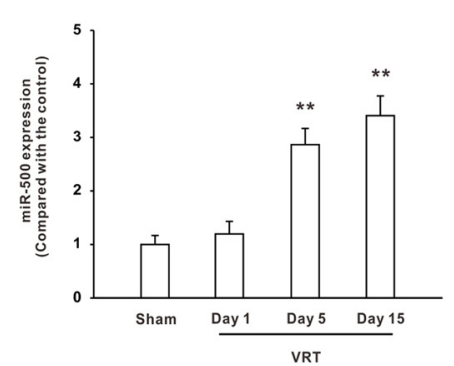

$\mathbf{E}$

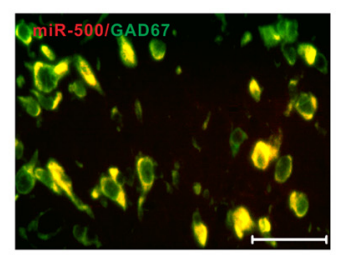

H

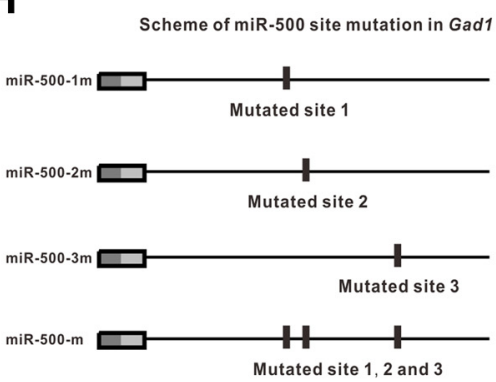

B

\begin{tabular}{|l|c|c|}
\hline \multirow{2}{*}{ miR name } & \multicolumn{2}{|c|}{$\begin{array}{c}\text { Fold-Change } \\
\text { (from Microarray) }\end{array}$} \\
\cline { 2 - 3 } & Day 4 & Day 10 \\
\hline miR-500 & 3.2 & 5.6 \\
\hline miR-188 & 2.9 & 3.4 \\
\hline miR-181 & 2.5 & 4.0 \\
\hline miR-331 & 2.7 & 4.2 \\
\hline
\end{tabular}

C

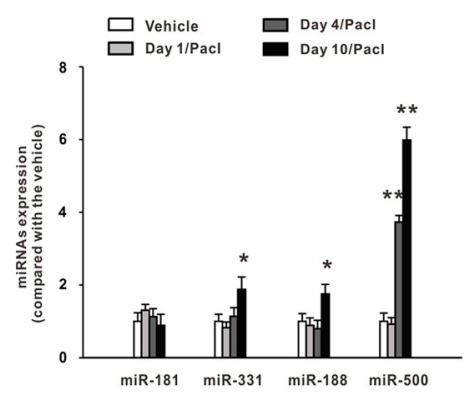

$\mathbf{F}$

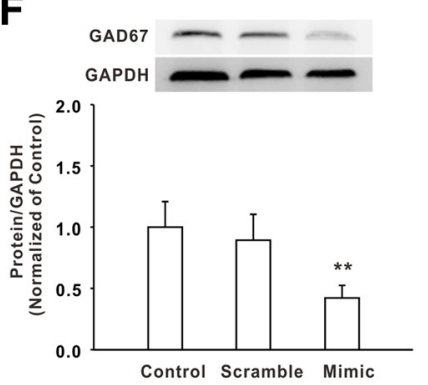

G

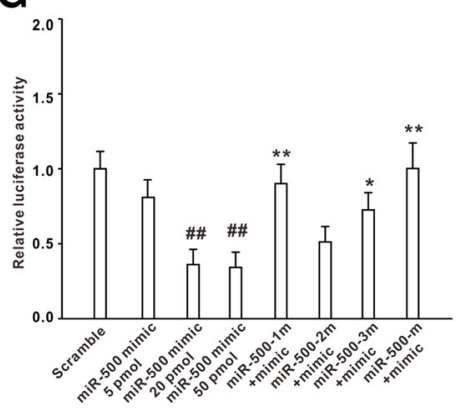

I

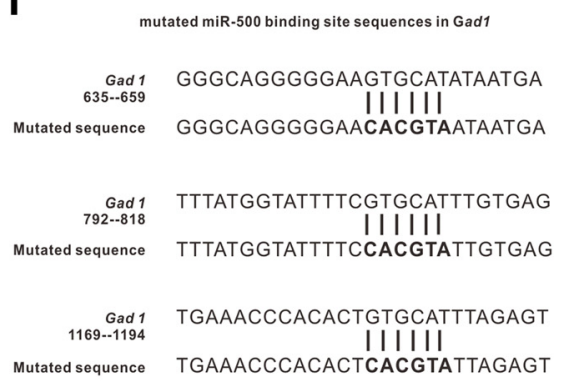

Figure 3. Increased mir-500 is induced by persistent pain directly regulated by GAD67 expression. $\boldsymbol{A}$, Heat maps of miRNAs found to be significantly upregulated via microarray analysis in the spinal dorsal horn of rats on days 4 and 10 after paclitaxel treatment compared with the vehicle group. $\boldsymbol{B}$, Database analysis showed that four miRNAs, including mir-500, mir-188, mir-181, and mir-331, are increased relative to the Gad1 gene. C, qRT-PCR analysis validated the upregulation of mir-500, mir-188, and mir-331, but not mir-181, after paclitaxel treatment. ${ }^{*} p<0.05,{ }^{* *} p<0.01$ versus corresponding vehicle group. $n=6$ in each group. D, Expression level of mir-500 in the spinal dorsal horn after L5-VRT. ${ }^{* *} p<0.01$ versus corresponding sham group. $n=6$ in each group. $\boldsymbol{E}$, FISH showed that mir-500 is coexpressed on GAD67-positive cells in the spinal dorsal horn. $\boldsymbol{F}$, Representative blots and histogram showing downregulation of GAD67 induced by mir-500 mimic in a C 6 cell. ${ }^{* *} p<0.01$ versus corresponding scramble group. $n=6$ in each group. $G$, Luciferase activity of reporter constructs containing either the $3^{\prime}$-UTR of Gad1 or mutated

increased on days 4 and 10, but not day 1 , after paclitaxel treatment (Fig. 3C). However, Mir-188 and mir-331 only had a significant increase on day 10 and mir-181 did not show a significantly change after paclitaxel treatment (Fig. 3C). Increased expression of mir-500 was also observed in the spinal dorsal horn at days 5 and 15 , but not day 1, after L5-VRT in the rats (Fig. 3D).

To verify whether mir-500 is actually involved in GAD67 expression, we first determined the expression of mir-500 and GAD67 using the FISH method. In all examined sections, 768 cells were GAD67positive and 576 were mir-500-positive. All (100\%) mir-500-positive cells were colocalized with the GAD67-positive cells in the spinal dorsal horn (Fig. 3E). To explore the functional association between mir-500 and GAD67, we transfected the mir-500 mimic into the $\mathrm{C} 6$ cells, which expressed a detectable amount of endogenous GAD67. The results showed that the mir-500 mimic significantly inhibited the GAD67 expression in C6 cells $1 \mathrm{~d}$ after transfection (Fig. 3F). Next, we constructed a luciferase reporter vector (psiCHECK2 vector) in which the 3 '-UTR of Gad1 was fused to the luciferase coding sequence. We then transfected human embryonic kidney 293 (HEK-293) cells with luciferase reporter vector and mir500 mimic. The results showed that mir500 mimic at dose of $20 \mathrm{pmol}$ or $50 \mathrm{pmol}$, but not 5 pmol, significantly reduced the luciferase signal compared with the scrambled control miRNA (Fig. $3 G$ ), suggesting that mir-500 directly targeted the 3'-UTR region of GAD67 mRNA to modulate its expression. Further silico analysis showed that mir-500 had three predicted binding sites in the $3^{\prime}$-UTR region of GAD67 mRNA, so we then generated mutant constructs for each of the sites individually (mir-500-1m, mir-500-2m, mir-500-3m) and a triple mutant with all three binding sites mutated (mir-500-m) in the 3'-UTR region of Gad1 (Fig. $3 \mathrm{H}, I$ ). We cotransfected the mutant constructs with the corresponding mir-500 mimic into HEK-293 cells and assessed the relative extent of inhibition. Mutation of the

Gad 1 site 1, site 2, and site 3 or mutated all of Gad 1 three sites, was cotransfected with mir500 mimic. \#\#p $<0.01$ versus scramble group, ${ }^{*} p<0.05,{ }^{* *} p<0.01$ versus mir500 mimic group. $n=6$. $H$, Schematic representation of $3^{\prime}$-UTR of Gad 1 gene demonstrating multiple mutated complementary binding sites of mir-500. $I$, Schematic representation of the specific mir-500 target sequence within the 3' UTR of Gad1. The seed sequence and mutated sequence are indicated by bold letters. 

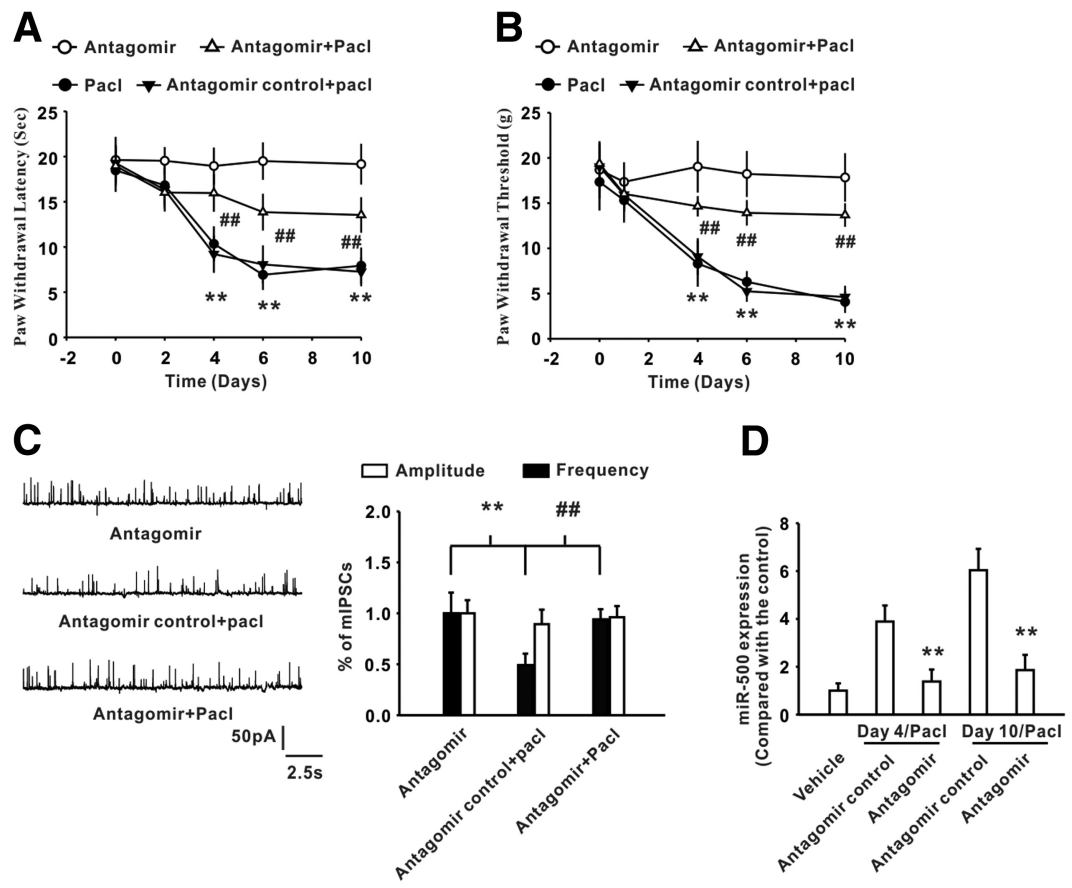

E

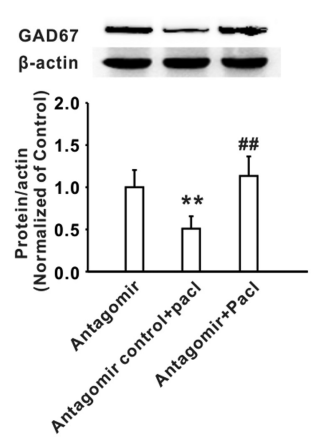

\section{$\mathbf{F}$}

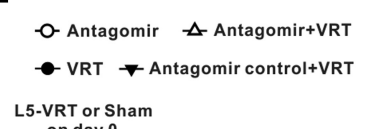
Lo 0

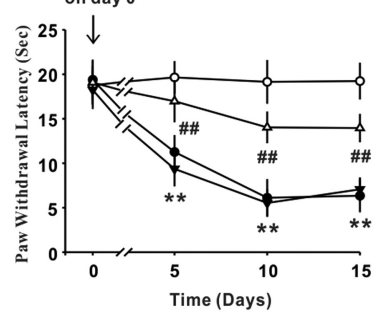

G

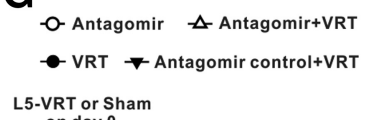
L5-VRT or Sham @2 $25 \downarrow$

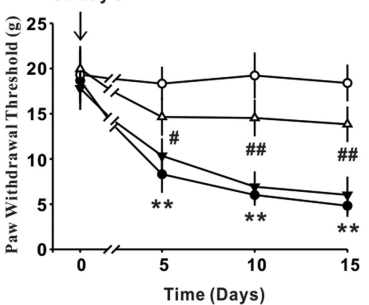

H

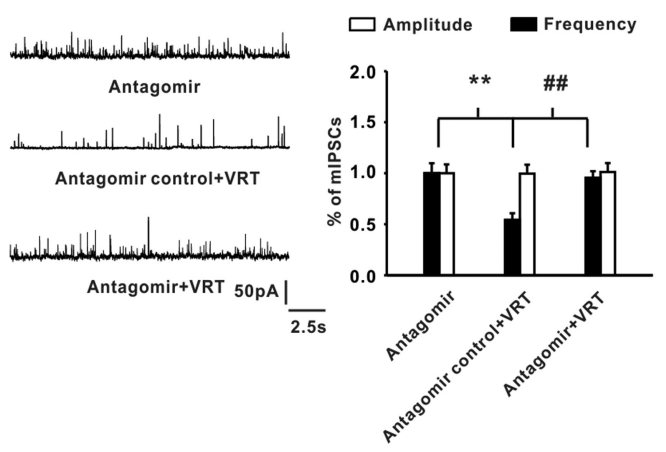

Figure 4. mir-500 modulates GABAergeic synapses and contributed to behavioral hypersensitivity. $A, B$, Intrathecal injection of mir-500 antagomir for 5 consecutive $d$ increased the withdrawal latency to thermal stimuli and withdrawal threshold to mechanical stimuli. ${ }^{* *} p<0.01$ versus antagomir group; \#\# $<0.01$ versus corresponding antagomir control + paclitaxel group. $n=12$ in each group. $C$, Intrathecal injection of mir-500 antagomir increased the frequency of mIPSCs after paclitaxel treatment. ${ }^{* *} p<$ 0.01 versus antagomir group; \#\#p $<0.01$ versus corresponding antagomir control + paclitaxel group. $n=51$ cells for each group. $D$, mir-500 antagomir significantly decreased mir-500 upregulation on days 4 and 10 after paclitaxel treatment. ${ }^{* *} p<0.01$ versus antagomir control group. $n=6$ for each group. $E$, Representative blots and histogram showing that mir-500 antagomir inhibited paclitaxel-induced downregulation of GAD67. ${ }^{* *} p<0.01$ versus antagomir group; \#\# $<0.01$ versus corresponding antagomir control + paclitaxel group. $n=12$ in each group. $\boldsymbol{F}, \mathbf{G}$, Intrathecal injection of mir-500 antagomir for 5 consecutive $d$ attenuated thermal hyperalgesia and mechanical allodynia induced by L5-VRT. ${ }^{* *} p<0.01$ versus antagomir group; \#p $<0.05$, \#\#p $<0.01$ versus corresponding antagomir control + L5-VRT group. $n=12$ in each group. $\boldsymbol{H}$, Intrathecal injection of mir-500 antagomir increased the frequency of mIPSCs in dorsal horn neurons in rats after L5-VRT. ${ }^{* *} p<0.01$ versus antagomir group; \#\#p $<0.01$ versus corresponding antagomir control + VRT group. $n=60$ cells for each group.

first predicted site in the $3^{\prime}$-UTR region of Gad1 (mir-500-1 m) significantly abolished the suppression of luciferase signal induced by mir-500 mimic and mutation in the third site (mir-500-3m) partially reversed the suppression of luciferase activity by the mir-500 mimic, whereas mutation in the second site (mir-500-1m) did not change mir-500 mimic-induced suppression (Fig. $3 G$ ). These results suggested that 635-659 in the $3^{\prime}$-UTR of Gad 1 was the critical site for mir-500 to regulate the expression of GAD67.

\section{mir-500 contributes to neuropathic pain via regulation of GAD67}

To assess the involvement of mir-500 in the induction of persistent pain, we blocked mir-500 function using a mir-500 antagomir. Antagomirs are synthetic miRNA inhibitors that are chemically modified for enhanced stability and cholesterol conjugated for high-efficiency delivery (Liang et al., 2014; Zhou et al., 2016). The results showed that intrathecal injection of mir-500 antagomir $(0.5 \mathrm{nmol} / \mathrm{d}$ for 5 consecutive $\mathrm{d})$ alone did not change the withdrawal latency to thermal stimuli (Fig. $4 A$ ) or the withdrawal threshold to mechanical stimuli in naive rats (Fig. 4B). However, compared with antagomir control, intrathecal injection of mir- 500 antagomir $(0.5 \mathrm{nmol} / \mathrm{d}$ for 5 consecutive d) significantly elevated the withdrawal latency (Fig. 4A) and withdrawal threshold (Fig. 4B) and increased the frequency of mIPSCs of superficial dorsal horn neurons in the rats treated with paclitaxel (Fig. 4C). qRT-PCR analyses showed that mir-500 antagomir significantly decreased the mir-500 upregulation on days 4 and 10 after paclitaxel treatment (Fig. 4D). Western blots also showed that mir-500 antagomir significantly increased the expression of GAD67 in the spinal dorsal horn on day 10 after initial treatment with paclitaxel (Fig. 4E). Similarly, mir-500 antagomir also inhibited thermal hyperalgesia (Fig. $4 F$ ) and mechanical allodynia (Fig. $4 G$ ) induced by L5-VRT and increased the frequency of mIPSCs of superficial dorsal horn neurons after L5-VRT (Fig. 4H). Notably, intrathecal injection of antagomir failed to affect the GAD67 expression, frequency of mIPSCs, and pain behavior in the control rats.

\section{KO of mir-500 increases mIPSC}

frequency and prevents behavioral hypersensitivity induced by paclitaxel or L5-VRT

To confirm the role of mir-500 in persistent pain, we created a mir-500 KO rat using TALENs. The newborn F2 rats were genotyped by PCR followed by DNA- 


\title{
DNA sequencing analysis of homozygotes F2
}

\author{
8 bases deletion (GCACCTGG) in the both strands.
}

\section{5'-tctgggtgcttagtgctatctcaatgcaat---------gcaagggttcagagaaggtgagctcatctgcagca-3' (-8)}
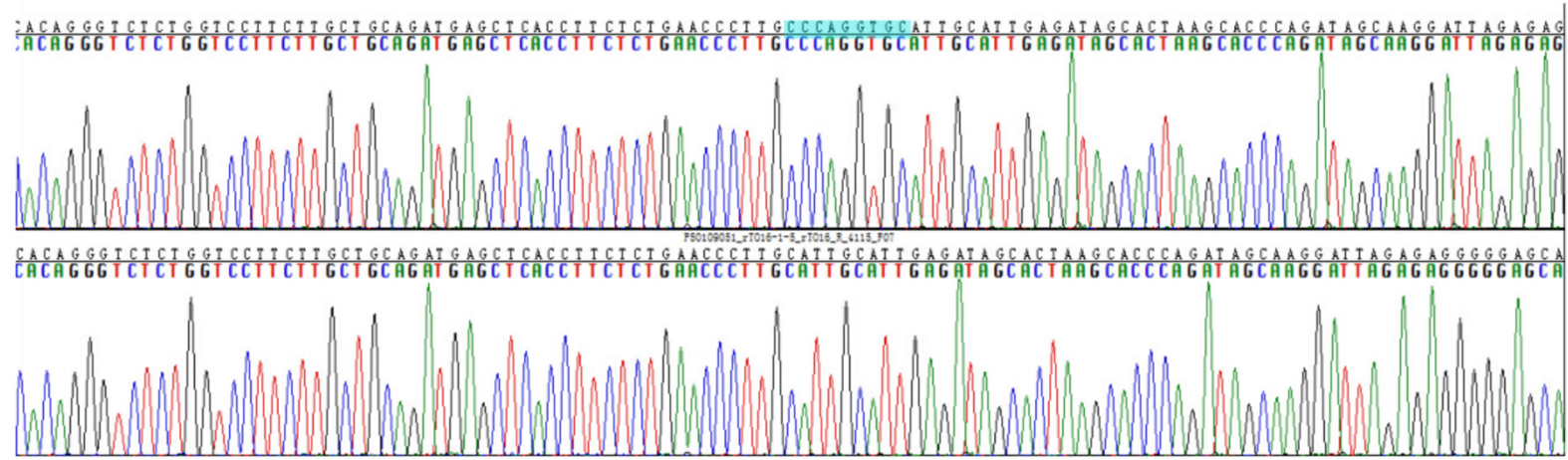

B

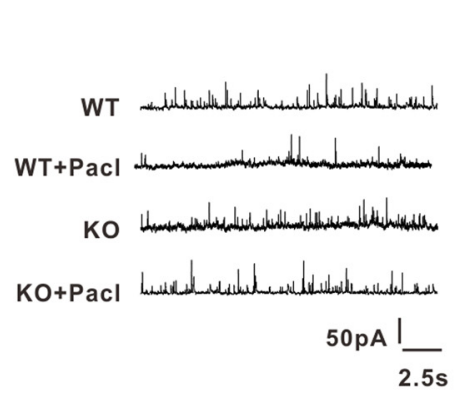

$\mathbf{E}$
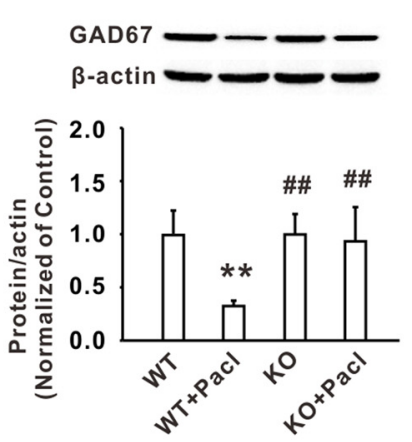

C

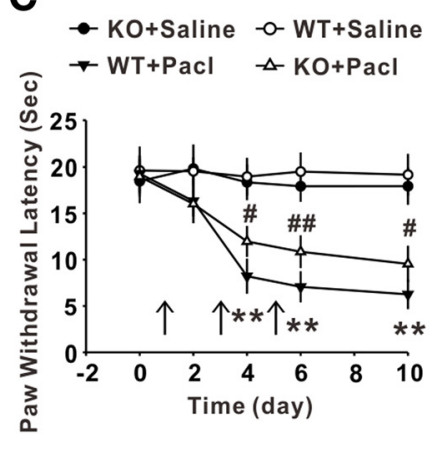

$\mathbf{F}$

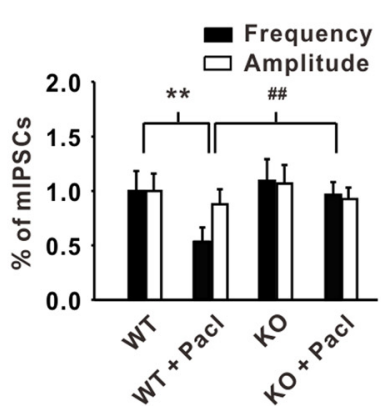

G
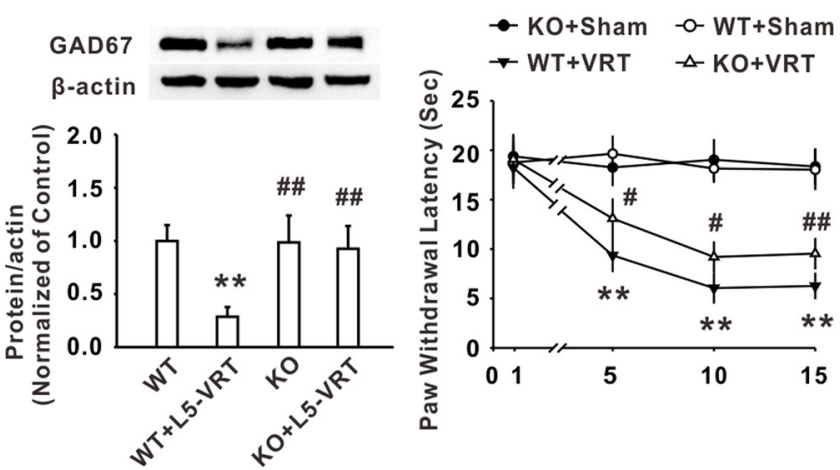

D

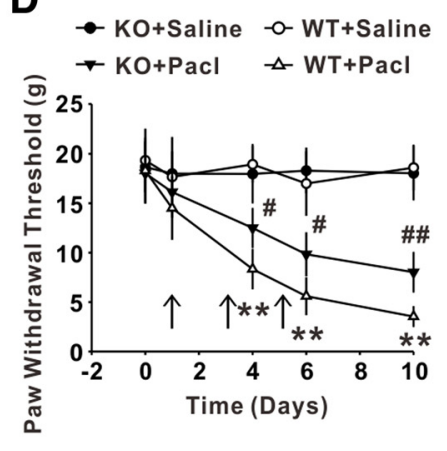

\section{H}

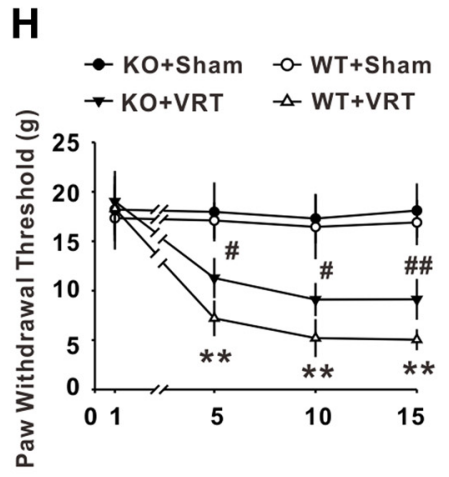

Figure 5. The KO of mir-500 increased mIPSC frequency and ameliorated the behavioral hypersensitivity induced by paclitaxel or L5-VRT. $A$, DNA-sequencing analysis showing that the F2 rats used for the experiment are homozygote rats for KO mir-500. The deleted bases are marked by blue. $\boldsymbol{B}, \mathrm{KO}$ of mir-500 increased the frequency of mIPSC in dorsal horn neurons. ${ }^{* *} p<0.01$ versus corresponding WT group; \#\# $<0.01$ versus corresponding WT + paclitaxel group. $n=52$ cells for each group. $C, D$, Withdrawal latency and withdrawal threshold were significantly increased in $K 0$ rats after paclitaxel treatment compared with WT rats also treated with paclitaxel. ${ }^{* *} p<0.01$ versus corresponding WT group; \#\# $<0.01$ versus WT + paclitaxel group. $n=12$ rats for each group. $\boldsymbol{E}, \boldsymbol{F}$, Representative blots and histogram showing that the K0 of mir-500 inhibited downregulation of GAD67 induced by paclitaxel or L5-VRT. ${ }^{* *} p<0.01$ versus WT group; \#\#p $<0.01$ versus corresponding WT + paclitaxel or WT + L5-VRT group. $n=12$ in each group. $\mathbf{G}, \boldsymbol{H}, \mathrm{KO}$ of mir-500 increased the withdrawal latency to thermal stimuli and withdrawal threshold to mechanical stimuli in rats after L5-VRT compared with those in WT rats after L5-VRT. ${ }^{* *} p<0.01$ versus corresponding WT group; \#p $<0.05$, \#\#p $<0.01$ versus corresponding WT + paclitaxel or WT + L5-VRT group. $n=12$ rats for each group.

sequencing analysis to identify homozygotes F2 (Fig. $5 A$ ). We used homozygote $\mathrm{F} 2$ rats ( $\mathrm{mir}-500^{-1-}$ ) to investigate the potential mir-500-mediated regulation of mIPSC frequency in the dorsal horn. The results showed that the frequency of mIPSCs in the $\mathrm{KO}$ rats was significantly increased compared with that in WT rats after paclitaxel treatment (Fig. 5B). Moreover, compared with the WT group, the KO rats exhibited a significant remission in thermal hyperalgesia (Fig. 5C) and mechanical allodynia (Fig.
5D) after paclitaxel treatment. Western blot analysis showed that GAD67 expression exhibited a significant recovery in the $\mathrm{KO}$ rats on day 10 after paclitaxel treatments (Fig. 5E). Similarly, the mir$500 \mathrm{KO}$ rats exhibited a significant recovery of GAD67 expression (Fig. 5F) and higher withdrawal latency (Fig. 5G) and withdrawal threshold (Fig. 5H) after the L5-VRT surgery. These results further confirmed that mir-500 plays an important role in the neuropathic pain induced by paclitaxel or L5-VRT. 


\section{Discussion}

In a rat model of neuropathic pain, we first showed that the chemotherapeutic drug paclitaxel or L5-VRT substantially enhanced mir-500 expression and consequently impaired inhibitory GABAergic transmission in spinal dorsal horn neurons, contributing to the development of persistent behavioral hypersensitivity. These results were supported by evidence that rats with mir-500 KO or treated with mir-500 antagomir demonstrated the rescue of GABA synaptic function in the spinal dorsal horn neurons and the attenuated pain behavior. In addition, in vivo and in vitro studies further showed that 635-659 in 3'-UTR of gad 1 might be the critical binding site for mir-500 to regulate the expression of GAD67. To our knowledge, this is the first study to investigate the functional significance of mir-500 and the underlying molecular mechanisms in rodent models of neuropathic pain, providing critical insights into how mir-500 participates in the regulation of GAD67 expression to contribute to the induction of neuropathic pain.

\section{Role of GAD67 in the spinal dorsal horn in neuropathic pain}

GAD67 is a critical enzyme for the synthesis of cytoplasmic GABA and control GABA vesicular filling and synaptic homeostasis (Lau and Murthy, 2012). Impaired synthesis and release of GABA may cause the loss of GABAergic inhibition, leading to the hyperexcitation of neurons. For instance, peripheral injury induces a loss of GABA inhibition in spinal neurons (Moore et al., 2002) and enhancing GABA synaptic inhibition alleviates injuryinduced pain (Knabl et al., 2008). Our results suggested that the chemotherapeutic drug paclitaxel or L5-VRT substantially downregulates GAD67 expression, leading to the impairment of GABA synaptic inhibition in the spinal dorsal horn and sensitized pain behavior. This was consistent with the previous reports that viral delivery of Gad1 reduces neuropathic pain (Liu et al., 2004b; Liu et al., 2008). In the present study, the downregulation of GAD67 was coincidently observed with the impairment of GABA synaptic inhibition in the dorsal horn neurons of the modeled rats, which was consistent with previous studies showing that cytosolic concentration of the GABA transmitter is a critical factor in its vesicular loading (Hartman et al., 2006) and that lack of GAD67 significantly decreases the GABA level (Asada et al., 1997). Previous studies also showed that homozygous deletion of Gad1 ( $\left.\mathrm{Gad1}^{-I^{-}}\right)$significantly reduces mIPSC amplitude and frequency in cultured hippocampal neurons from newborn mice pups (Lau and Murthy, 2012), whereas the frequency, but not amplitude, of mIPSCs was slightly, though insignificantly, decreased in Gad1 ${ }^{+/-}$neurons (Lau and Murthy, 2012). These results implied that adaptation of mIPSCs was largely dependent on the content of GAD67. In the present study, substantial reduction of GAD67 was observed in the dorsal horn neurons, which might be responsible for the decreased mIPSC frequency and attenuated GABAergic input-output response in rodent models of neuropathic pain.

Furthermore, studies have shown that paclitaxel treatment and direct nerve damage may induce a number of neuroinflammatory responses, including increases of proinflammatory cytokines in the dorsal horn. These cytokines, including TNF- $\alpha$ and IL-6, suppress GABA-mediated IPSCs via TNFR1 and the IL6R (Kawasaki et al., 2008; Zhang et al., 2013). However, whether these proinflammatory cytokines suppressed GAD67 expression, thus leading to GABAergic suppression in dorsal horn and behavioral sensitization, needs to be further studied in the setting of neuropathic pain. The mechanism underlying GAD67 reduction was complex among the different tissues. For example, various factors such as transcription factors Zif268 (Yanagawa et al., 1997), histone acetylation (Tremolizzo et al., 2002), and DNA methylation (Kundakovic et al., 2007) participated in GAD67 expression via modification of the Gad1 promoter. The present study provided a novel theory of the mechanism underlying GAD67 downregulation in the spinal dorsal horn that mir-500 may affect the function of GAD67 mRNA and, consequently, mediate the reduction of GAD67 in spinal dorsal horn neurons after paclitaxel treatment or L5-VRT. Furthermore, neuropathic pain generally involves the altered expression of many genes (Lacroix-Fralish et al., 2007) and it is likely that other genes in addition to Gad1 are also the targets of persistent pain-induced chromatin remodeling. GAD65 is another key rate-limiting-rate and is targeted preferentially to presynaptic terminals of central neurons for GABA synthesis (Tian et al., 1999; Patel et al., 2006). Studies have showed that GAD65 in different regions could participate in pain regulation by decreasing inhibition among neurons through reducing the levels of cellular GABA (Gwak and Hulsebosch, 2011; Zhang et al., 2011; Lorenzo et al., 2014). For example, suppression of Gad2 transcription through histone hypoacetylation in brainstem nucleus raphe magnus results in the impairment of GABA synaptic function and sensitized pain behavior (Zhang et al., 2011). Our data showed an important role of GAD67 in the spinal dorsal horn in pain modulation, whereas this did not completely preclude a potential involvement of GAD65. We note that the detailed mechanism by which GAD65 might play a role in pain modulation needs further study.

\section{Role of mir-500-mediated targeting of GAD67 in neuropathic pain}

Several studies have revealed the dysregulation of miRNA expression in the spinal cord under neuropathic pain conditions (Genda et al., 2013; Elramah et al., 2014), whereas the intracellular processes largely remained elusive. Intrathecal injection of mir-124 had an obvious antinociceptive effect in rodents with inflammation or nerve injury (Willemen et al., 2012). Using a miRNA microarray, the present study showed that four miRNAs, including mir-500, mir-188, mir-181, and mir-331, were significantly increased in the spinal dorsal horn after paclitaxel treatment ( $>2.5$-fold change) compared with the vehicle group. qRT-PCR analysis further confirmed that mir-500 exhibited the most significant increase and the pattern was consistent with paclitaxel-induced behavioral hypersensitivity. Similarly, an increase of mir-500 was also observed in the dorsal horn in rats after L5-VRT. These results were supported by the observation that mir-500 incurred a significant increase in the bladder smooth muscle cells of patients with bladder pain syndrome (Sanchez Freire et al., 2010). All these studies suggested that mir-500 might be a critical molecule to mediating pain syndromes. Although our present results and those of others (Arai et al., 2013) suggested that miR-188 might be involved in hyperalgesia, the function of miR-188 was not investigated in the current study, mainly because mir-500 had a much greater increase in spinal dorsal horn after paclitaxel treatment. Notably, we provided the morphological evidence to demonstrate the distribution of mir-500 in GABAergic neurons in the dorsal horn and also identified the machinery for the direct binding of mir-500 in the critical site (635-659) in the GAD67 mRNA sequence. These results strongly implied a potential role of mir-500 in the modulation of GAD67 expression in the dorsal horn in rodent models of neuropathic pain. In the present study, we first reported that inhibition of mir- 500 by KO or antagomir remarkably attenuated the GAD67 reduction and suppression of GABAergic transmission in the 
dorsal horn, as well as the behavioral hypersensitivity in the rats after paclitaxel treatment or L5-VRT. It is well known that multiple mechanisms appear to be responsible for neuropathic pain, including ectopic activity in primary afferents, induction of central sensitization, and loss of inhibition (GABAergic neurons and/or glycinergic) in the spinal dorsal horn (Sivilotti and Woolf, 1994; Woolf and Mannion, 1999). In the present study, we only observed the modulation of GABAergic IPSCs in superficial dorsal horn neurons in rodent models of neuropathic pain. Therefore, it is reasonable that mir-500 antagomir treatment completely restored GABA-mediated IPSC frequency, yet the behavioral responses did not return to the baseline level. Together, the present results show for the first time a mir-500-involved mechanism to regulate GABAergic transmission in that dorsal horn and contribute to the induction of neuropathic pain in a rodent model.

\section{References}

Arai M, Genda Y, Ishikawa M, Shunsuke T, Okabe T, Sakamoto A (2013) The miRNA and mRNA changes in rat hippocampi after chronic constriction injury. Pain Med 14:720-729. CrossRef Medline

Asada H, Kawamura Y, Maruyama K, Kume H, Ding RG, Kanbara N, Kuzume H, Sanbo M, Yagi T, Obata K (1997) Cleft palate and decreased brain gamma-aminobutyric acid in mice lacking the $67-\mathrm{kDa}$ isoform of glutamic acid decarboxylase. Proc Natl Acad Sci U S A 94:6496-6499. CrossRef Medline

Baccei ML, Fitzgerald M (2004) Development of GABAergic and glycinergic transmission in the neonatal rat dorsal horn. J Neurosci 24:4749-4757. CrossRef Medline

Bai G, Ambalavanar R, Wei D, Dessem D (2007) Downregulation of selective microRNAs in trigeminal ganglion neurons following inflammatory muscle pain. Mol Pain 3:15. CrossRef Medline

Bartel DP (2009) MicroRNAs: target recognition and regulatory functions. Cell 136:215-233. CrossRef Medline

Chattopadhyaya B, Di Cristo G, Wu CZ, Knott G, Kuhlman S, Fu Y, Palmiter RD, Huang ZJ (2007) GAD67-mediated GABA synthesis and signaling regulate inhibitory synaptic innervation in the visual cortex. Neuron 54: 889-903. CrossRef Medline

Chen C, Ridzon DA, Broomer AJ, Zhou Z, Lee DH, Nguyen JT, Barbisin M, Xu NL, Mahuvakar VR, Andersen MR, Lao KQ, Livak KJ, Guegler KJ (2005) Real-time quantification of microRNAs by stem-loop RT-PCR. Nucl Acids Res 33:e179. CrossRef Medline

Elramah S, Landry M, Favereaux A (2014) MicroRNAs regulate neuronal plasticity and are involved in pain mechanisms. Front Cell Neurosci 8:31. CrossRef Medline

Esclapez M, Tillakaratne NJ, Kaufman DL, Tobin AJ, Houser CR (1994) Comparative localization of two forms of glutamic acid decarboxylase and their mRNAs in rat brain supports the concept of functional differences between the forms. J Neurosci 14:1834-1855. Medline

Filipowicz W, Bhattacharyya SN, Sonenberg N (2008) Mechanisms of posttranscriptional regulation by microRNAs: are the answers in sight? Nat Rev Genet 9:102-114. CrossRef Medline

Genda Y, Arai M, Ishikawa M, Tanaka S, Okabe T, Sakamoto A (2013) microRNA changes in the dorsal horn of the spinal cord of rats with chronic constriction injury: A TaqMan (R) Low Density Array study. Int J Mol Med 31:129-137. CrossRef Medline

Gwak YS, Hulsebosch CE (2011) GABA and central neuropathic pain following spinal cord injury. Neuropharmacology 60:799-808. CrossRef Medline

Gwak YS, Tan HY, Nam TS, Paik KS, Hulsebosch CE, Leem JW (2006) Activation of spinal GABA receptors attenuates chronic central neuropathic pain after spinal cord injury. J Neurotrauma 23:1111-1124. CrossRef Medline

Hargreaves K, Dubner R, Brown F, Flores C, Joris J (1988) A new and sensitive method for measuring thermal nociception in cutaneous hyperalgesia. Pain 32:77-88. CrossRef Medline

Hartman KN, Pal SK, Burrone J, Murthy VN (2006) Activity-dependent regulation of inhibitory synaptic transmission in hippocampal neurons. Nat Neurosci 9:642-649. CrossRef Medline

Huang ZZ, Li D, Liu CC, Cui Y, Zhu HQ, Zhang WW, Li YY, Xin WJ (2014)
CX3CL1-mediated macrophage activation contributed to paclitaxelinduced DRG neuronal apoptosis and painful peripheral neuropathy. Brain Behav Immun 40:155-165. CrossRef Medline

Kawasaki Y, Zhang L, Cheng JK, Ji RR (2008) Cytokine mechanisms of central sensitization: distinct and overlapping role of interleukin-1beta, interleukin-6, and tumor necrosis factor-alpha in regulating synaptic and neuronal activity in the superficial spinal cord. J Neurosci 28:5189-5194. CrossRef Medline

Kim VN, Han J, Siomi MC (2009) Biogenesis of small RNAs in animals. Nat Rev Mol Cell Biol 10:126-139. CrossRef Medline

Knabl J, Witschi R, Hösl K, Reinold H, Zeilhofer UB, Ahmadi S, Brockhaus J, Sergejeva M, Hess A, Brune K, Fritschy JM, Rudolph U, Möhler H, Zeilhofer HU (2008) Reversal of pathological pain through specific spinal GABA(A) receptor subtypes. Nature 451:330-334. CrossRef Medline

Kundakovic M, Chen Y, Costa E, Grayson DR (2007) DNA methyltransferase inhibitors coordinately induce expression of the human reelin and glutamic acid decarboxylase 67 genes. Mol Pharmacol 71:644-653. Medline

Lacroix-Fralish ML, Ledoux JB, Mogil JS (2007) The Pain Genes Database: an interactive web browser of pain-related transgenic knockout studies. Pain 131:3 e1-e4. Medline

Lau CG, Murthy VN (2012) Activity-dependent regulation of inhibition via GAD67. J Neurosci 32:8521-8531. CrossRef Medline

Li D, Huang ZZ, Ling YZ, Wei JY, Cui Y, Zhang XZ, Zhu HQ, Xin WJ (2015) Up-regulation of CX3CL1 via nuclear factor-kappaB-dependent histone acetylation is involved in paclitaxel-induced peripheral neuropathy. Anesthesiology 122:1142-1151. CrossRef Medline

Li L, Xian CJ, Zhong JH, Zhou XF (2002) Effect of lumbar 5 ventral root transection on pain behaviors: a novel rat model for neuropathic pain without axotomy of primary sensory neurons. Exp Neurol 175:23-34. CrossRef Medline

Liang H, Gu Y, Li T, Zhang Y, Huangfu L, Hu M, Zhao D, Chen Y, Liu S, Dong Y, Li X, Lu Y, Yang B, Shan H (2014) Integrated analyses identify the involvement of microRNA-26a in epithelial-mesenchymal transition during idiopathic pulmonary fibrosis. Cell Death Dis 5:e1238. CrossRef Medline

Li S, Chen X, Zhang H, Liang X, Xiang Y, Yu C, Zen K, Li Y, Zhang CY (2009) Differential expression of microRNAs in mouse liver under aberrant energy metabolic status. J Lipid Res 50:1756-1765. CrossRef Medline

Liu CC, Lu N, Cui Y, Yang T, Zhao ZQ, Xin WJ, Liu XG (2010) Prevention of paclitaxel-induced allodynia by minocycline: Effect on loss of peripheral nerve fibers and infiltration of macrophages in rats. Mol Pain 6:76. CrossRef Medline

Liu CG, Calin GA, Meloon B, Gamliel N, Sevignani C, Ferracin M, Dumitru CD, Shimizu M, Zupo S, Dono M, Alder H, Bullrich F, Negrini M, Croce CM (2004a) An oligonucleotide microchip for genome-wide microRNA profiling in human and mouse tissues. Proc Natl Acad Sci U S A 101:9740-9744. CrossRef Medline

Liu J, Wolfe D, Hao S, Huang S, Glorioso JC, Mata M, Fink DJ (2004b) Peripherally delivered glutamic acid decarboxylase gene therapy for spinal cord injury pain. Mol Ther 10:57-66. CrossRef Medline

Liu W, Liu Z, Liu L, Xiao Z, Cao X, Cao Z, Xue L, Miao L, He X, Li W (2008) A novel human foamy virus mediated gene transfer of GAD67 reduces neuropathic pain following spinal cord injury. Neurosci Lett 432:13-18. CrossRef Medline

Lorenzo LE, Magnussen C, Bailey AL, St Louis M, De Koninck Y, Ribeiro-daSilva A (2014) Spatial and temporal pattern of changes in the number of GAD65-immunoreactive inhibitory terminals in the rat superficial dorsal horn following peripheral nerve injury. Mol Pain 10:57. CrossRef Medline

Malan TP, Mata HP, Porreca F (2002) Spinal GABA(A) and GABA(B) receptor pharmacology in a rat model of neuropathic pain. Anesthesiology 96:1161-1167. CrossRef Medline

Martin DL (2000) The two isoforms of glutamate decarboxylase and GABA compartmentation in brain. J Neurochem 74:S44.

Moore KA, Kohno T, Karchewski LA, Scholz J, Baba H, Woolf CJ (2002) Partial peripheral nerve injury promotes a selective loss of GABAergic inhibition in the superficial dorsal horn of the spinal cord. J Neurosci 22:6724-6731. Medline

Patel AB, de Graaf RA, Martin DL, Battaglioli G, Behar KL (2006) Evidence that GAD65 mediates increased GABA synthesis during intense neuronal activity in vivo. J Neurochem 97:385-396. CrossRef Medline

Sanchez Freire V, Burkhard FC, Kessler TM, Kuhn A, Draeger A, Monastyrskaya K (2010) MicroRNAs may mediate the down-regulation of 
neurokinin-1 receptor in chronic bladder pain syndrome. Am J Pathol 176:288-303. CrossRef Medline

Schuler V, et al. (2001) Epilepsy, hyperalgesia, impaired memory, and loss of pre- and postsynaptic $\mathrm{GABA}(\mathrm{B})$ responses in mice lacking GABA(B(1)). Neuron 31:47-58. CrossRef Medline

Sengupta JN, Pochiraju S, Pochiraju S, Kannampalli P, Bruckert M, Addya S, Yadav P, Miranda A, Shaker R, Banerjee B (2013) MicroRNA-mediated GABA Aalpha-1 receptor subunit down-regulation in adult spinal cord following neonatal cystitis-induced chronic visceral pain in rats. Pain 154:59-70. CrossRef Medline

Sivilotti L, Woolf CJ (1994) The contribution of GABAA and glycine receptors to central sensitization: disinhibition and touch-evoked allodynia in the spinal cord. J Neurophysiol 72:169-179. Medline

Tian N, Petersen C, Kash S, Baekkeskov S, Copenhagen D, Nicoll R (1999) The role of the synthetic enzyme GAD65 in the control of neuronal gamma-aminobutyric acid release. Proc Natl Acad Sci U S A 96:1291112916. CrossRef Medline

Tremolizzo L, Carboni G, Ruzicka WB, Mitchell CP, Sugaya I, Tueting P, Sharma R, Grayson DR, Costa E, Guidotti A (2002) An epigenetic mouse model for molecular and behavioral neuropathologies related to schizophrenia vulnerability. Proc Natl Acad Sci U S A 99:17095-17100. CrossRef Medline

Vaysse L, Sol JC, Lazorthes Y, Courtade-Saidi M, Eaton MJ, Jozan S (2011) GABAergic pathway in a rat model of chronic neuropathic pain: modulation after intrathecal transplantation of a human neuronal cell line. Neurosci Res 69:111-120. CrossRef Medline

Willemen HL, Huo XJ, Mao-Ying QL, Zijlstra J, Heijnen CJ, Kavelaars A (2012) MicroRNA-124 as a novel treatment for persistent hyperalgesia. J Neuroinflammation 9:143. CrossRef Medline
Woolf CJ, Mannion RJ (1999) Neuropathic pain: aetiology, symptoms, mechanisms, and management. Lancet 353:1959-1964. CrossRef Medline

Wu D, Raafat M, Pak E, Hammond S, Murashov AK (2011) MicroRNA machinery responds to peripheral nerve lesion in an injury-regulated pattern. Neuroscience 190:386-397. CrossRef Medline

Yanagawa Y, Kobayashi T, Kamei T, Ishii K, Nishijima M, Takaku A, Tamura S (1997) Structure and alternative promoters of the mouse glutamic acid decarboxylase 67 gene. Biochem J 326:573-578. CrossRef Medline

Yoshimura M, Nishi S (1993) Blind patch-clamp recordings from substantia gelatinosa neurons in adult rat spinal cord slices: pharmacological properties of synaptic currents. Neuroscience 53:519-526. CrossRef Medline

Zang Y, Chen SX, Liao GJ, Zhu HQ, Wei XH, Cui Y, Na XD, Pang RP, Xin WJ, Zhou LJ, Liu XG (2015) Calpain-2 contributes to neuropathic pain following motor nerve injury via up-regulating interleukin-6 in DRG neurons. Brain Behav Immun 44:37-47. CrossRef Medline

Zhang H, Zhang H, Dougherty PM (2013) Dynamic effects of TNF-alpha on synaptic transmission in mice over time following sciatic nerve chronic constriction injury. J Neurophysiol 110:1663-1671. CrossRef Medline

Zhang Z, Cai YQ, Zou F, Bie B, Pan ZZ (2011) Epigenetic suppression of GAD65 expression mediates persistent pain. Nat Med 17:1448-1455. CrossRef Medline

Zhou S, Wang Y, Meng Y, Xiao C, Liu Z, Brohawn P, Higgs BW, Jallal B, Jia Q, Qu B, Huang X, Tang Y, Yao Y, Harley JB, Shen N (2015) In vivo therapeutic success of microRNA-155 (miR-155) antagomir in a mouse model of lupus alveolar hemorrhage. Arthritis Rheumatol 68:953-964. CrossRef Medline 